\title{
GAMBARAN PELAKSANAAN PROGRAM PENGELOLAAN PENYAKIT KRONIS (PROLANIS) PASIEN HIPERTENSI DI PUSKESMAS LAWANGGINTUNG KOTA BOGOR TAHUN 2018
}

\section{Imaroh Isnadia, Husnah Maryati, Asri Masitha Arsyati}

${ }^{1}$ Konsentrasi Manajemen Pelayanan Kesehatan, Program Studi Kesehatan Masyarakat, Fakultas Ilmu Kesehatan Universitas Ibn Khaldun Bogor. E-mail : imarohisnadia@gmail.com

2,3Program Studi Kesehatan Masyarakat, Fakultas Ilmu kesehatan Universitas Ibn Khaldun Bogor.

\begin{abstract}
Abstrak
Prolanis merupakan salah satu strategi promotif dan preventif yang dilakukan oleh BPJS Kesehatan untuk menurunkan atau mencegah komplikasi penyakit kronis yang diderita oleh peserta sekaligus sebagai kendali biaya pelayanan kesehatan. Penelitian ini bertujuan untuk mengetahui gambaran pelaksanaan program Prolanis pada pasien hipertensi di Puskesmas Lawangintung Kota Bogor tahun 2018. Penelitian ini menggunakan metode kualitatif dengan jenis rancangan deskriptif. Informan terdiri dari 6 orang terdiri dari Kepala Puskesmas, Penanggung Jawab Prolanis, Petugas Pelaksana Prolanis, dan Peserta Prolanis. Instrumen penelitian yang digunakan yaitu pedoman wawancara mendalam. Hasil penelitian menunjukkan bahwa dari faktor input yaitu ketersediaan SDM sudah cukup, serta tersedianya sarana dan prasarana untuk kegiatan. Puskesmas Lawanggintung tidak melakukan klaim dana kegiatan Prolanis dan tidak memiliki SOP khusus terkait pelaksanaan Prolanis. Hasil dari proses pelaksanaan kegiatan Prolanis di Puskesmas Lawanggintung secara umum sudah bagus dan masih berjalan sampai saat ini. Hasil dari faktor output bahwa klub PPHT Prolanis Puskesmas Lawanggintung terkontrol dan berhasil mencapai indikator $75 \%$ peserta memperoleh hasil baik pada pemeriksaan bulan Oktober 2018. Peneliti menyarankan agar BPJS Kesehatan Pusat untuk membuat standar Operasional Prosedur (SOP) program Prolanis bagi FKTP, karena dengan adanya SOP diharapkan PIC dan petugas pelaksana Prolanis dapat bekerja secara lebih terarah dan rinci sesuai standar yang berlaku.

Kata Kunci : Prolanis, BPJS Kesehatan, Hipertensi
\end{abstract}

\section{PENDAHULUAN}

Penyakit Tidak Menular (PTM) merupakan salah satu masalah kesehatan yang menjadi perhatian nasional maupun global. Masalah PTM pada akhirnya tidak hanya menjadi masalah kesehatan saja, namun bila tidak dikendalikan secara tepat, benar dan kontinyu akan dapat mempengaruhi ketahanan ekonomi nasional, karena sifatnya yang kronis dan umumnya mengenai usia produktif.

Penyakit Tidak Menular (PTM) juga dikenal sebagai penyakit kronis dan tidak ditularkan dari satu orang ke orang lainnya. Penyakit- penyakit ini memiliki durasi panjang dan umumnya berkembang lambat. Laporan dari Word Health Organization (WHO) tahun 2014 menunjukkan bahwa PTM sejauh ini merupakan penyebab kematian utama di dunia. Terdapat 38 juta kematian dari 56 juta angka kematian dunia pada tahun 2012 disebabkan oleh PTM. Sebanyak tiga-perempat dari kematian yang disebabkan PTM (28 juta) terjadi di 
negara miskin dan negara berkembang.

Penyakit tidak menular yang menjadi masalah kesehatan di Indonesia adalah hipertensi dan diabetes. Hipertensi didefinisikan sebagai kenaikan tekanan darah sistolik $\geqq 140 \mathrm{mmHg}$ dan tekanan darah diastolik $\geqq 90 \mathrm{mmHg}$. Hipertensi merupakan salah satu penyakit yang paling umum ditemukan dalam praktik kedokteran primer. Menurut NHLBI (National Heart, Lung, and Blood Institute) satu dari tiga pasien menderita hipertensi. Hipertensi juga merupakan faktor risiko infark miokard, stroke, gagal ginjal akut, dan kematian.

Berdasarkan Riset Kesehatan Dasar (RISKESDAS) 2013 prevalensi hipertensi pada penduduk umur 18 tahun ke atas di Indonesia adalah sebesar 25,8\%. Prevalensi hipertensi tertinggi di provinsi Bangka Belitung (30,9\%) dan terendah di provinsi Papua (16,8\%). Provinsi Kalimantan Selatan, Kalimantan Timur, dan Jawa Barat merupakan provinsi yang mempunyai prevalensi hipertensi lebih tinggi dari angka nasional.

Berdasarkan UU Nomor 36 tahun 2009 Tentang Kesehatan, dikatakan bahwa setiap orang mempunyai hak dalam memperoleh pelayanan kesehatan yang aman, bermutu, dan terjangkau (Pasal 5 ayat 2 UU No. 36 Tahun 2009). Agar amanat tersebut terwujud, maka ditetapkan Undang-Undang Nomor 40 Tahun 2004 tentang Sistem Jaminan Sosial Nasional (SJSN) untuk memberikan jaminan sosial yang menyeluruh bagi seluruh rakyat Indonesia. Untuk mewujudkan tujuan dari SJSN, kemudian dibentuk Badan Penyelenggara Jaminan Sosial (BPJS) melalui Undang Undang Nomor 24 Tahun 2011. Pada Januari 2014 PT. ASKES melakukan transformasi menjadi BPJS Kesehatan untuk menjalankan Jaminan Kesehatan Nasional tersebut.

Jaminan Kesehatan Nasional (JKN) terdapat pelayanan Program Pengelolaan Penyakit Kronis (PROLANIS) sebagai salah satu program di Puskesmas. Besarnya pembiayaan kesehatan penyakit kronis merupakan latar belakang BPJS Kesehatan mengembangkan PROLANIS, selain besarnya pembiayaan kesehatan untuk penyakit kronis dan hal-hal lain yang melatarbelakangi pengembangan PROLANIS yaitu risiko penyakit peserta terdaftar di BPJS Kesehatan tidak diketahui, peningkatan kelompok usia lanjut, meningkatnya trend penyakit degeneratif, risiko terjadinya adverse selection pada awal pelaksanaan Jaminan Kesehatan Nasional (JKN).

Sasaran dari program ini adalah seluruh peserta BPJS Kesehatan yang memiliki atau beresiko penyakit hipertensi dan diabetes melitus tipe 2. Prolanis bertujuan untuk mendorong peserta penyandang penyakit kronis mencapai kualitas hidup yang optimal dengan biaya pelayanan kesehatan yang efektif dan efisien. Dengan indikator 75\% peserta terdaftar berkunjung ke Faskes Tingkat Pertama memiliki hasil "baik" pada pemeriksaan spesifik terhadap penyakit DM Tipe 2 dan Hipertensi sesuai panduan klinis terkait sehingga dapat mencegah timbulnya komplikasi penyakit (BPJS Kesehatan, 2014).

Prolanis terdiri dari 6 aktivitas, yaitu : (a) Konsultasi medis peserta prolanis, (b) edukasi kelompok, (c) reminder melalui SMS gateway, (d) home visit, (e) aktivitas klub, (f) pemantauan status kesehatan (BPJS Kesehatan, 2014).

Kegiatan Prolanis ini tentunya sangat bermanfaat bagi kesehatan para pengguna peserta BPJS. Komitmen peserta dalam mengikuti Prolanis juga merupakan hal yang sangat penting. Peserta diharapakan mengikuti semua ketentuan pengobatan yang direncanakan, karena jika tidak ada komitmen maka program ini akan gagal. 
Prolanis memiliki target peningkatan status kesehatan, pengetahuan, kemampuan, dan kesadaran peserta dalam rangka pemeliharaan kesehatan secara mandiri dapat terwujud secara maksimal. Target ini juga didasarkan pada panduan klinis yang berlaku. Indikator keberhasilan program ini adalah terwujudnya Profil Kesehatan Peserta melalui pemantauan berkesinambungan terhadap peserta. Hal ini bertujuan agar jumlah peserta yang hidup sehat dengan penyakit kronis dapat dioptimalkan dan peserta yang jatuh pada fase akut/penyakit menjadi semakin rentan dapat diminimalisasi.

Berdasarkan data BPJS Kesehatan Kantor Cabang Umum (KCU) Kota Bogor, hingga bulan Januari 2019 jumlah FKTP yang melaksanakan Prolanis berjumlah 51 FKTP, dengan jumlah Klub Pengelola Penyakit Hipertensi (PPHT) adalah 51 dan jumlah Klub Pengelola Penyakit DM Tipe 2 (PPDM) sebanyak 46 klub.

Kota Bogor memiliki Fasilitas Kesehatan Tingkat Pertama (FKTP) sebanyak 24 Puskesmas. Puskesmas Lawanggintung merupakan salah satu fasilitas kesehatan tingkat pertama (FKTP) yang ada di Kota Bogor. Profil Kesehatan Kota Bogor tahun 2017 menunjukan bahwa angka kesakitan tertinggi pada kasus Hipertensi terdapat di Puskesmas Lawanggintung yaitu sebesar 35,8\% dengan 1.675 kasus dari 12.658 jumlah kasus hipertensi yang ada di Kota Bogor.

Puskesmas Lawanggintung sudah melaksanakan program Prolanis sejak tahun 2016, namun angka hipertensi di wilayah kerja Puskesmas Lawanggintung masih tinggi. Oleh karena itu maka dibutuhkan penelitian tentang gambaran pelaksanaan program prolanis di Puskesmas Lawanggintung Kota Bogor Tahun 2018.

\section{METODE}

Jenis penelitian ini menggunakan metode penelitian kualitatif. Metode kualitatif merupakan pendekatan untuk mengetahui hal-hal yang lebih dalam dari sebuah fenomena.

Penelitian ini dilaksanakan pada bulan Oktober tahun 2018 di wilayah kerja Puskesmas Lawanggintung Jalan Skip No. 13 Kelurahan Lawang Gintung Kecamatan Bogor Selatan.

Populasi dalam penelitian ini adalah pasien hipertensi berjumlah 10 orang yang terdaftar sebagai peserta prolanis di Puskesmas Lawanggintung. Dalam penelitian ini subjek yang menjadi informan inti adalah kepala Puskesmas, dokter penanggung jawab program Prolanis, dan bidan sebagai petugas pelaksana program Prolanis. Sedangkan yang menjadi informan kunci adalah peserta Prolanis.

Instrumen yang digunakan dalam penelitian ini, yaitu pedoman wawancara mendalam yang diadopsi dari penelitian terdahulu (Pratiwi, 2017), lembar check list observasi, alat perekam suara menggunakan recorder handphone, kertas dan alat tulis, kamera handphone sebagai alat dokumentasi. Analisis data menggunakan triangulasi sumber yang dilakukan dengan cara cross check data dengan fakta dari sumber lain yaitu peserta Prolanis yang berperan sebagai informan kunci, dan triangulasi metode menggunakan metode wawancara mendalam yang ditunjang dengan metode observasi pada saat wawancara dilakukan. 


\section{HASIL DAN PEMBAHASAN KARAKTERISTIK INFORMAN}

\section{Input}

a. Sumber Daya Manusia

sumber daya manusia yang berperan dalam pelaksanaan program Prolanis dan peserta Prolanis mengetahui definisi dan tujuan dari pelaksanaan prolanis, yaitu program yang mengelola penyakit kronis dan dapat mendeteksi dini penyakit tersebut Petugas pelaksana program Prolanis berjumlah 5 orang terdiri dari dokter sebagai penanggung jawab program dan bidan sebagai pemegang program dan dibantu oleh 3 orang kader. Untuk pelaksanaan Prolanis mereka melakukan kegiatan dilapangan bersama. Menurut peneliti dengan jumlah SDM 2 (dua) orang dan 3 kader untuk melaksanakan program prolanis ini dianggap sudah cukup. Karena peserta Prolanis yang di kelola Puskesmas berjumlah 20 (dua puluh) orang.

b. Sumber Daya Keuangan Sumber daya keuangan pelaksanaan Prolanis di Puskesmas bersumber dari BPJS Kesehatan Kota Bogor dengan sistem reimburse. Setiap bulan Puskesmas menyerahkan laporan kegiatan pelaksanaan Prolanis ke BPJS Kesehatan kota Bogor dan melakukan klaim untuk dana pelaksanaan prolanis. Besaran anggaran untuk setiap kegiatan juga telah ditentukan oleh BPJS Kesehatan Kota Bogor, sehingga tidak ada perbedaan sumber daya keuangan untuk pelaksanaan prolanis di Puskemas. Akan tetapi, Puskesmas lawanggintung jarang mengajukan klaim dana. Dikarenakan tidak ada biaya yang dikeluarkan dalam melaksanakan kegiatan Prolanis.

\section{c. Sarana dan Prasarana}

Sarana dan prasarana yang dibutuhkan terkait pelaksanaan Prolanis sudah tersedia di Puskesmas, hanya saja untuk ruang pelaksana Prolanis tidak tersedia di Puskesmas. Dikarenakan keterbatasan ruangan. Pelaksanaan Prolanis dilakukan di Posyandu RW 04, dimana mayoritas peserta Prolanis berada di wilayah RW 04.

\section{d. Peraturan}

Puskesmas Lawanggintung tidak memiliki peraturan khusus terkait pelaksanaan program Prolanis. Kegiatan Prolanis di Puskesmas Lawanggintung dilakukan sebulan sekali, akan tetapi tanggal di setiap bulannya berbeda-beda tergantung bagaimana jadwal yang diberikan oleh dokter pelaksana.

Puskesmas Lawanggintung hanya menggunakan panduan yang diberikan BPJS Kesehatan mengenai pelaksanaan program Prolanis. Meskipun Prolanis tidak memiliki SOP khusus, tetapi Puskesmas Lawanggintung memiliki struktur petugas pelaksana dan pembagian tugas yang jelas. Seperti dokter sebagai penanggung jawab kegiatan dan bidan sebagai pelaksana kegiatan.

\section{Proses}

a. Konsultasi Medis

Jadwal untuk konsultasi medis disepakati bersama antara peserta dengan fasilitas kesehatan pengelola. Berdasarkan hasil wawancara dengan informan, jadwal konsultasi medis ditentukan oleh dokter yang bertanggungjawab dalam program Prolanis. Konsultasi medis 
dilakukan satu bulan sekali. Pada saat pemeriksaan kesehatan seperti pemeriksaan tekanan darah dan pemeriksaan gula darah, apabila didapati hasil pemeriksaan tinggi, maka dokter akan memberikan edukasi kepada peserta. Peserta biasanya langsung melakukan konsultasi kepada dokter mengenai keluhan yang dirasa.

\section{b. Reminder melalui SMS Gateway}

Petugas pelaksana Prolanis sudah melaksanakan kegiatan ini secara rutin ketika akan ada kegiatan Prolanis. Pemberitahuan jadwal untuk kegiatan pelaksanaan Prolanis dilakukan oleh dokter. Dokter memberi kabar kepada kader melalui pesan whatsapp. Setelah itu kader memberikan kabar tersebut kepada para peserta dengan cara door to doo. Pemberitahuan jadwal kegiatan Prolanis dilakukan dokter kepada kader prolanis dua hari sebelum waktu pelaksanaan.

\section{c. Home Visit}

Kegiatan kunjungan rumah dilakukan petugas Prolanis apabila terdapat peserta yang sudah beberapa kali tidak bisa hadir pada saat kegiatan pemeriksaan dikarenakan sakit. Puskesmas Lawanggintung pernah melakukan home visit satu kali.

\section{d. Edukasi Kelompok}

Edukasi kelompok dilakukan dalam bentuk penyuluhan oleh dokter pelaksana Prolanis. Materi yang disampaikan berhubungan dengan penyakit hipertensi dan diabetes melitus. Kegiatan tersebut dilakukan satu bulan sekali dan dilakukan setelah selesai pemeriksaan kesehatan peserta. Peserta juga aktif bertanya apabila terdapat materi yang kurang dimengerti. Sehingga pengetahuan mengenai kesehatan peserta meningkat.

\section{e. Aktivitas Klub}

Aktivitas klub yang dilaksanakan Puskesmas Lawanggintung adalah senam. Kegiatan senam telah dilaksanakan terlebih dahulu oleh warga RW 04 sebelum Puskesmas Lawanggintung menjalankan Prolanis. Sehingga peserta Prolanis yang mayoritas berada di wilayah RW 04 dapat langsung mengikuti kegiatan senam tersebut. Kegiatan senam dilaksanakan pada hari selasa, kamis, dan sabtu dimulai pada pukul 07.00 WIB. Kegiatan senam Prolanis sudah berjalan rutin. Tetapi tidak semua peserta Prolanis ikut dalam kegiatan tersebut, dikarenakan banyak peserta Prolanis yang sudah berusia lanjut.

\section{f. Pemantauan Status Kesehatan}

Pemantauan status kesehatan dilakukan satu bulan sekali untuk dilihat perkembangan status kesehatan peserta. Pemeriksaan yang dilakukan berupa pengukuran tekanan darah, gula darah, pengukuran tinggi badan, berat badan, dan lingkar perut peserta. Hasil pemeriksaan tersebut di catat dalam buku status kesehatan oleh kader Prolanis. Sehingga dapat dilihat penurunan atau kenaikan status kesehatan peserta dapat dilihat di kontrol. Pencatatan hasil pemeriksaan kesehatan peserta dianggap cukup penting, karna dengan hasil yang dicatat tersebut dapat dilihat perkembangan status kesehatan peserta. Apakah terjadi penurunan atau kenaikan. Sehingga memudahkan dokter untuk mengambil tindakan selanjutnya yang 
akan diberikan kepada peserta.

\section{Output}

Hasil pemeriksaan kesehatan peserta Prolanis di Puskesmas Lawanggintung dapat dilihat bahwa peserta klub PPHT terkontrol dan berhasil mencapai indikator 75\% peserta memperoleh hasil baik pada pemeriksaan bulan Oktober 2018.

\section{KESIMPULAN DAN SARAN}

\section{Input}

a. Sumber Daya Manusia (SDM)

Ketersediaan sumber daya manusia dalam pelaksanaan Prolanis sudah tercukupi dan pembagian tugas yang cukup jelas. Hal ini dapat dilihat dari semua informan yang mengungkapkan SDM yang ada telah mencukupi. Sedangkan untuk pasien hipertensi yang mengikuti Prolanis yaitu sebanyak 10 orang.

b. Sumber Daya Keuangan Pelaksanaan Prolanis berasal

dari BPJS Kesehatan dengan sistem reimburse. Akan tetapi Puskesmas Lawanggintung tidak melakukan klaim dana, dikarenakan tidak ada biaya yang dikeluarkan dalam pelaksanaan kegiatan Prolanis.

c. Peraturan

Peraturan dalam pelaksanaan program Prolanis Puskesmas Lawanggintung tidak memiliki peraturan khusus, hanya saja mengikuti panduan praktis Prolanis BPJS Kesehatan.

d. Sarana dan prasarana

Sarana dan Prasarana dalam menunjang kelangsungan program Prolanis sudah tercukupi, akan tetapi dari segi ruangan Puskesmas

Lawanggintung tidak memiliki ruangan untuk melaksanakan kegiatan Prolanis dikarenakan keterbatasan ruangan. Kegiatan Prolanis dilakukan di Posyandu RW 04.

\section{2. process}

Pelaksanaan kegiatan Prolanis di Puskesmas Lawanggintung secara umum sudah bagus dan masih berjalan sampai saat ini. Puskesmas Lawanggintung telah melaksanakan kegiatan yang telah ditetapkan oleh BPJS Kesehatan yaitu konsultasi medis, edukasi kelompok, reminder melalui SMS gateway, aktivitas klub, dan juga pemantauan status kesehatan, akan tetapi untuk home visit hanya dilakukan apabila terdapat peserta yang tidak bisa hadir untuk mengikuti kegiatan Prolanis dikarenakan sakit.

\section{Output}

Perkembangan status kesehatan peserta Prolanis beragam pada setiap peserta dan setiap bulannya. Berdasarkan hasil pemeriksaan tekanan darah 3 bulan terakhir klub PPHT Prolanis Puskesmas Lawanggintung terkontrol dan berhasil mencapai indikator $75 \%$ peserta memperoleh hasil baik pada pemeriksaan bulan Oktober 2018. 


\section{Saran}

a. Sebaiknya Puskesmas Lawanggintung menambah jumlah peserta Prolanis klub PPHT, agar pasien yang terdiagnosa hipertensi dapat ikut menjadi peserta Prolanis dan tekanan darahnya menjadi terkontrol. Sehingga angka hipertensi di Puskesmas Lawanggintung menurun.

b. Disarankan kepada BPJS Kesehatan Pusat untuk membuat standar Operasional Prosedur (SOP) program Prolanis bagi FKTP, karena dengan adanya SOP diharapkan PIC dan petugas pelaksana Prolanis dapat bekerja secara lebih terarah dan rinci sesuai standar yang berlaku.

c. Kepada Peneliti Selanjutnya, peserta BPJS penderita hipertensi dianjurkan untuk menjadi peserta Prolanis, akan tetapi masih banyak peserta BPJS penderita hipertensi yang tidak ikut serta dalam klub Prolanis. Untuk selanjutnya dapat dilakukan penelitian mengenai alasan peserta BPJS penderita hipertensi tidak ikut menjadi peserta Prolanis dan bagaimana perkembangan kondisi kesehatan mereka.

\section{DAFTAR PUSTAKA}

Azwar, Azrul. Pengantar Administrasi Kesehatan Edisi Ke Tiga. Jakarta: PT.Binarupa Aksara Arsyati Asri Masitha, 2019, pengaruh penyuluhan media audiovisual dalam pengetahuan pencegahan stunting pada ibu hamil di desa cibatok 2 cibungbulang pengaruh penyuluhan media audiovisual dalam Pengetahuan pencegahan stunting pada ibu hamil di desa, PROMOTOR Jurnal Mahasiswa Kesehatan Masyarakat, Vol. 2 No. 3, Juni 2019

Asri Masitha Arsyati, Vindi Krisna Chandra, 2020. Assement Kesiapan Kader Posyandu dalam Pelatihan Penggunaan Media Online. HEARTY Jurnal Kesehatan Masyarakat Vol.8 No.1, 2020 Agustus-February, hlm. 27-32 ISSN. 2338-7475 E-ISSN. 2620-7869

Arsyati, Asri Masitha ; Hadi Pratomo, Irawati Ismail, Sabarinah Prasetyo, Rita Damayanti. (2017). Pengembangan Media Cetak Pendidikan Pencegahan Kekerasan Seksual Balita Di Kota Bogor. Hearty Jurnal Kesmas, Vol.5 no.1 tahun 2017. Penerbit Universitas Ibn Kahldun Bogor. http://ejournal.uika-bogor.ac.id/index.php/Hearty/article/view/1052

Arsyati, A.M., \& Rahayu, Y.T. (2019). Budaya pemberian makanan pendamping ASI (MP-ASI) pada bayi usia kurang dari bulan di desa Leuwibatu Rumpin. Jurnal kesehatan masyarakat, 7(1), 9-17

A Nasution, A Maulana, D Kurniawan. (2019). BERSAMA MEMAJUKAN DESA. Abdi Dosen: Jurnal Pengabdian Pada Masyarakat 3 (2), 99-104

BPJS Kesehatan, (2014). Panduan Praktis PROLANIS. Jakarta: BPJS Kesehatan.

Dinas Kesehatan Kota Bogor. (2017). Profil Kesehatan Kota Bogor 2017. Bogor: Dinas Kesehatan Kota Bogor

Fitrianingtyas, Pertiwi, dan Rachmania, W. Faktor-Faktor yang Berhubungan dengan Kejadian Kurang Energi Kronis (KEK) pada Ibu Hamil di Puskesmas Warung Jambu Kota Bogor. HEARTY Jurnal Kesehatan Masyarakat. 2018;6(2):1-8.

Hayajneh, Y. (2007). Systems \& Systems Theory. Dalam Management for Health Care Professionals Series

Hanissa, J., Nasution, A., \& Arsyati, A. M. 2017. "Gambaran Perilaku Personal Hygiene Menstruasi Remaja Putri Yang Mengikuti Pelatihan Dan Pembinaan Pkpr Di Smp Pgri 13 
Wilayah Kerja Puskesmas Sindang Barang Kota Bogor Tahun 2017". Hearty Jurnal Kesehatan Masyarakat, 5(2).

Latifah, Ita. (2017). Analisis Pelaksanaan Program Pengelolaan Penyakit Kronis (Prolanis) BPJS Kesehatan pada Psien Hipertensi di UPTD Puskesmas Tegal Gundil Kota Bogor Tahun 2017. Skripsi: Bogor. Program Sarjana Kesehatan Masyarakat Universitas Ibn Khaldun Bogor

Mardotillah, A. A. (2016). Implementasi Pelaksanaan Program Pengelolaan Penyakit Kronis (Prolanis) di BPJS Kesehatan Kantor Cabang Jakarta Timur Tahun 2016. Skripsi. Depok: Program Sarjana Kesehatan Masyarakat Universitas Indonesia

Mariyamah ,S., Asri M. A., Ade Saputra N. (2020). Respon Mahasiswa Terhadap Pictorial

Health Warning di Fakultas Teknik Universitas Ibn Khaldun Tahun 2020. Jurnal Mahasiswa Kesehatan Masyarakat. Vol. 3 No. 5

Notoatmodjo, S. (2010). Metodologi Penelitian Kesehatan. Jakarta: Rineka Cipta

Peraturan Menteri Kesehatan No 28 tahun 2014 tentang Pedoman Pelaksanaan Jaminan Kesehatan Nasional

Pratiwi, N. L. P. A (2017). Gambaran Pelaksanaan Program Pengelolaan Penyakit Kronis (Prolanis) di Fasilitas Kesehatan Tingkat Pertama (FKTP) Wilayah Kerja BPJS Kesehatan Kota Bogor tahun 2017. Skripsi. Depok: Program Sarjana Kesehatan Masyarakat Universitas Indonesia

Putri, T. K. (2017). Evaluasi Implementasi Program Pengelolaan Penyakit Kronis (Prolanis) di BPJS Kesehatan Kantor Cabang Depok Tahun 2017. Skripsi: Depok. Program Sarjana Kesehatan Masyarakat Universitas Indonesia

Pusat Data dan Informasi Kementrian kesehatan republik indonesia, (2014). Tentang Hipertensi. Jakarta: Kementrian Kesehatan

Pertiwi, F. D., Hariansyah, M., \& Prasetya, E. P. (2019). FAKTOR RISIKO STUNTING PADA BALITA DIKELURAHAN MULYAHARJA TAHUN 2019. PROMOTOR, 2(5). https://doi.org/10.32832/pro.v2i5.2531

Pertiwi, F. D., Rahman, R. M., \& Lestari, D. W. (2018). Pemberdayaan masyarakat melalui bidang literasi di Desawaru Jaya. Jurnal ABDI DOSEN: Jurnal Pengabdian Pada Masyarakat, 2(2), 129-137. https://doi.org/10.32832/abdidos.v2i2.170

Rinata, F., Arsyati, A. M., \& Maryati, H. (2019). Gambaran Implementasi Program Rujuk Balik (Prb) Bpjs Kesehatan Di Puskesmas Wilayah Kerja Kecamatan Tanah Sareal Kota Bogor .... Promotor.

Rochmawati, D., \& Arsyati, A. M. J. P. (2019). Gambaran Keterpaparan Media Berkonten Pornografi Pada Anak-Anak Peserta Didik Kelas 4, 5 Dan 6 Di Sdn Kayu Manis 2 Kota Bogor. 2(5), 351-360.Ngadiran, Antonius (2010). Studi Fenomenologi Pengalaman Keluarga Tentang Beban dan Sumber Dukungan Keluarga Dalam Merawat Klien Dengan Halusinasi. Tesis. Depok, FIK-UI

Undang-Undang No. 24 tahun 2011 tentang Badan Penyelenggara Jaminan Sosial. 